\title{
Outcome of Traumatic bilateral basal ganglia Hemorrhage: Rarest entity: Prospective study of five cases: Single institutional Experience
}

\author{
Neha Gupta ${ }^{1}$, Vivek Kumar Kankane ${ }^{2}$, Tarun Kumar Gupta ${ }^{3}$ \\ ${ }^{1}$ Ananta Institute of Medical Science, Udaipur, INDIA \\ ${ }^{2}$ Department of Neurosurgery, SMS Medical College, Jaipur (Rajasthan) INDIA \\ ${ }^{3}$ Department of Neurosurgery, R.N.T. Medical College, Udaipur (Rajasthan) INDIA
}

\begin{abstract}
Traumatic Basal ganglia hemorrhage is rare entity but bilateral basal ganglia hematoma after trauma is extremely rare and is limited to case reports. We describe five cases of traumatic bilateral basal ganglia hemorrhage, and its outcome and management. All Cases were managed conservatively. The general incidence of TBGH is reported between $2.4-3 \%$ of closed head injury. However, the incidence is higher in post mortem studies $(9.8 \%)$. Five consecutive patients of TBGH, shown in initial Noncontrast CT (NCCT) head, admitted in our institute from August 2013 to August 2016, during this period total patient admitted of head injury is 1061 so incidence of Traumatic bilateral basal ganglia Hemorrhage in our series is $0.47 \%$ which is very less compare to previous literature formed the prospective study group. There were 3 males and 2 females; age ranging from 20 to 45 years (average 30 years).Hypertensive patients, drugs abuse history, history of coagulopathy with doubtful history of trauma or unknown mode of injury was excluded from the study. All patients had sustained road traffic accidents. NCCT head done of all patients after initial resuscitation. GCS at admission were 9 to 12 (mean 10.4), Outcome assessed by Glasgow outcome Score. All patients outcome was good. Average follow up 8.54 months.
\end{abstract}

Key words: basal ganglia, trauma, bilateral, memorrhage

\section{Introduction}

Traumatic Basal ganglia hemorrhage (TBGH) is defined as a hemorrhagic lesion located in the basal ganglia or neighboring structures such as internal capsule or thalamus. TBGH is relatively uncommon
[1,2, and 3]. An incidence of $3-10 \%$ of head injuries has been reported $[1,3,4]$ The incidence is higher in autopsy series when compared with clinical studies [1,3] Bilateral basal ganglia hematoma after trauma is extremely rare and is limited to case reports 
$[4,5]$ The mechanism is unclear though it is proposed to arise from shear strain of the lenticulostriate or anterior choroid vessels caused by acceleration/deceleration forces at the time of injury $[1,6]$. The fact that Basal ganglia hematoma can be due to trauma but its takes importance in the medico legal cases where bleeding may be attributed to a non traumatic cause. Thus, the recognition of TBGH is of prime relevance.

\section{Material \& Method}

Five consecutive patients of TBGH, shown in initial Noncontrast CT (NCCT) head, admitted from January 2012 to January 2017 in the Department of Neurosurgery at R.N.T. Medical College and M.B. Hospital, Udaipur, Rajasthan, formed the Prospective Study group. A written informed consent was taken from of all patients, as applicable. The diagnosis of TBGH was made on the basis on NCCT and Outcome assessed by Glasgow outcome score.

\section{Results}

During study period total patient admitted of head injury is 1061 so incidence of Traumatic bilateral basal ganglia Hemorrhage in our series is $0.47 \%$ which is very less compare to previous literature formed the prospective study group. There were 3 males and 2 females; age ranging from 20 to 45 years (average 30 years (Table1)). Hypertensive patients, drugs abuse history, history of coagulopathy with doubtful history of trauma or unknown mode of injury was excluded from the study. All patients had sustained road traffic accidents. NCCT head done of all patients after initial resuscitation. GCS at admission were 9 to 12 (mean 10.4), Outcome assessed by Glasgow outcome Score (Table 2). All patients outcome was good, outcome were labeled as excellent (GOS-5), fair (GOS-4) and poor (GOS1-3) average follow up 8.54 months. We described all patients detailed in case descriptions (Case-1 to Case-5).

Table 1 - Demography, management and outcome of patient

\begin{tabular}{|l|l|l|l|l|l|l|l|}
\hline $\begin{array}{c}\text { Serial } \\
\text { No. }\end{array}$ & Age & Sex & Mode of injury & $\begin{array}{c}\text { GCS at the time } \\
\text { of admission }\end{array}$ & $\begin{array}{r}\text { Focal } \\
\text { neurological } \\
\text { deficit }\end{array}$ & Management & $\begin{array}{c}\text { Outcome } \\
\text { measure by } \\
\text { GOS }\end{array}$ \\
\hline 1 & $20 \mathrm{yr}$ & Male & $\begin{array}{l}\text { RTA(Road } \\
\text { traffic accident })\end{array}$ & $9 / 15$ & $\begin{array}{l}\text { Right side } \\
\text { Hemiparesis }\end{array}$ & Conservative & Excellent(5) \\
\hline 2 & $40 \mathrm{yr}$ & Male & RTA & $9 / 15$ & $\begin{array}{l}\text { Left side } \\
\text { Hemiparesis }\end{array}$ & Conservative & Excellent(5) \\
\hline 3 & $35 \mathrm{yr}$ & Female & RTA & $10 / 15$ & No & Conservative & Excellent(5) \\
\hline 4 & $25 \mathrm{yr}$ & Female & RTA & $12 / 15$ & No & conservative & Excellent(5) \\
\hline 4 & $30 \mathrm{yr}$ & Male & RTA & $12 / 15$ & No & Conservative & Excellent(5) \\
\hline
\end{tabular}


Table 2 - Glasgow outcome score

\begin{tabular}{ll}
\hline GOS Score & Functional status \\
\hline $\mathbf{5}$ & Resumption of normal life; there may be minor neurological and or psychological deficit \\
$\mathbf{4}$ & Able to work in a shattered environment and travel by public transportation \\
$\mathbf{3}$ & Dependent for daily support by reason of mental or physical disability or both \\
$\mathbf{2}$ & Unresponsive for weeks or months or until death \\
$\mathbf{1}$ & Death \\
\hline
\end{tabular}

\section{Case 1}

20 year old male admitted in neurosurgery ward with head injury in unconscious state. There was no history of ear bleed, nose bleed, convulsion, CSF leak. There was no history of significant illness, substance abuse, or any history suggestive of any bleeding disorder. Patient was a non-diabetic non-hypertensive. Prior to the accident, he was not on any medication. His Glasgow Coma Scale (GCS) was E1V3M5. Pupils were $2 \mathrm{~mm}$ bilaterally, reacting to light. Right side grade 3 hemiparesis present. A NCCT Brain showed Deep Intracerebral bleed [Figure 1A] in the basal ganglia involving the corona radiata on the right (approximately $11 \mathrm{~mm}$ by $14 \mathrm{~mm}$ ) and left (approximately $18 \mathrm{~mm}$ by $14 \mathrm{~mm}$ ). Sulcal spaces and basal cisterns were normal and no midline shift. All blood parameters and clotting profile were within normal limits. Antibiotic \& phenytoin sodium was given. 2nd of admission patient became conscious, oriented \& GCS was 15/15 but Hemiparesis is still present with improvement of grade 3 to grade 4,3 month of follow up of patient was alright without any Hemiparesis , GCS 15/15 and advised repeat NCCT head which revealed complete resolution of Hemorrhage [Figure 1B].

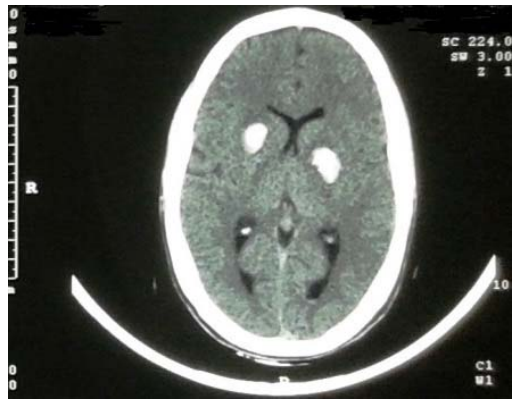

Figure 1A - Deep Intracerebral bleed in the basal ganglia involving the corona radiata on the right (approximately $11 \mathrm{~mm}$ by $14 \mathrm{~mm}$ ) and left (approximately $18 \mathrm{~mm}$ by $14 \mathrm{~mm}$ )

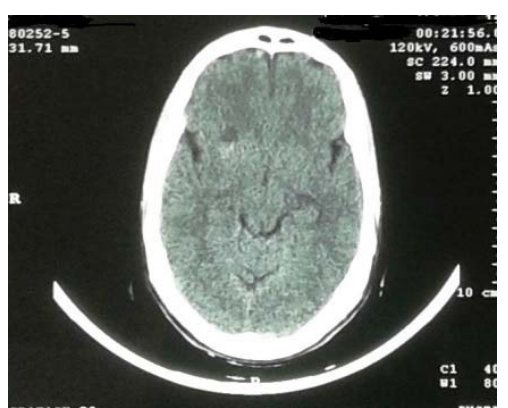

Figure 1B - Complete resolution of bilateral basal ganglia Hemorrhage

\section{Case 2}

45 year old male, met with a Road traffic accident when he was riding a motor cycle and was hit by another motor cycle. History of loss of consciousness and nose bleed was present, there was no history of ear bleed, and convulsion vomiting \& CSF leak .His GCS was E2V3M5. Pupils were $2 \mathrm{~mm}$ bilaterally, 
reacting to light. Left side Hemiparesis grade 3 was present. Plain Computerized Tomogram (CT) showed Intracerebral bleed [Figure 2A] in the basal ganglia involving the corona radiate \& capsuloganglionic region on the right (approximately $22 \mathrm{~mm}$ by $17 \mathrm{~mm}$ ) and left capsuloganglionic region (approximately $3 \mathrm{~mm}$ by $2 \mathrm{~mm}$ ) and multiple hemorrhagic contusions are seen right temporal lobe. Basal cisterns were normal no midline shift. All blood parameters and clotting profile were within normal limits. Primary suturing of wound and Antibiotic \& phenytoin sodium was given. 3rd day of admission patient became conscious but Hemiparesis was still present which was improved to grade 3 to grade 4 on 8 th day of admission, Patient was discharge 10th day of admission 3 month of follow up of patient was alright without any Hemiparesis and advised repeat NCCT head which revealed complete resolution of Hemorrhage [Figure 2B].

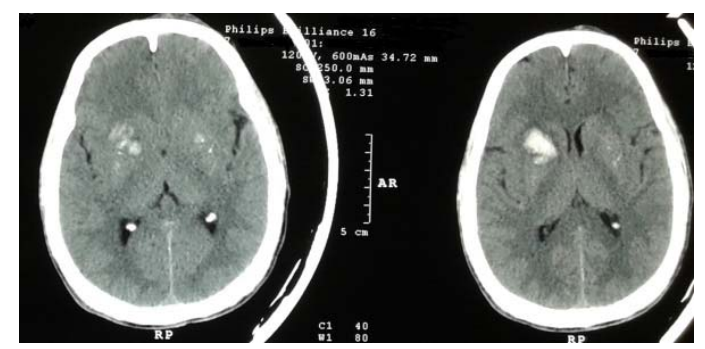

Figure 2A - Intracerebral bleed in the basal ganglia involving the corona radiate \& capsuloganglionic region on the right (approximately $22 \mathrm{~mm}$ by $17 \mathrm{~mm}$ ) and left capsuloganglionic region (approximately 3 $\mathrm{mm}$ by $2 \mathrm{~mm}$ ) and multiple hemorrhagic contusions are seen right temporal lobe

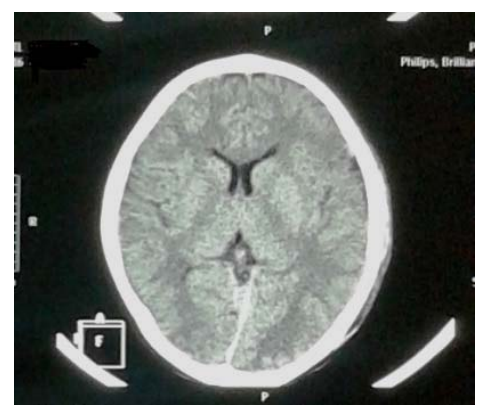

Figure 2B - Complete resolution of bilateral basal ganglia Hemorrhage

\section{Case 3}

35 year old Female, was admitted with History of Road traffic accident in neurosurgery ward in unconscious state. There was no history of ear bleed, nose bleed, convulsion, CSF leak. There was no any history suggestive of any bleeding disorder. Patient was a non-diabetic non-hypertensive. His GCS was E2V3M5. Pupils were $2 \mathrm{~mm}$ bilaterally, reacting to light. Bilateral limb movement was equal. A plain Computerized Tomogram (CT) showed Deep Intracerebral bleed [Figure 3A] in the bilateral basal ganglia which was mirror image to each other, it was also a rarest presentation on imaging. Basal cisterns were normal and no midline shift. All blood parameters and clotting profile were within normal limits. Phenytoin sodium was given. 2nd of admission patient became conscious, oriented \& GCS was 15/15 and no focal neurological deficit, then Patient was discharge 5th of admission. 3 month of follow up of patient was alright without any neurological deficit, and advised repeat NCCT head which revealed complete resolution of Hemorrhage [Figure 3B]. 


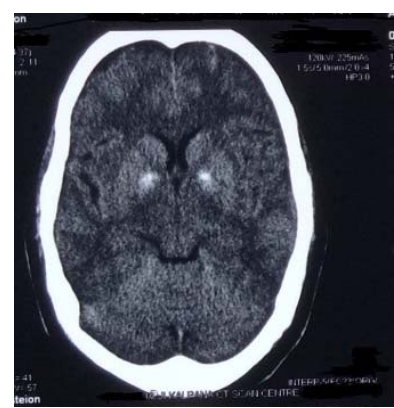

Figure 3A - showed Deep Intracerebral bleed in the bilateral basal ganglia which was mirror image to each other

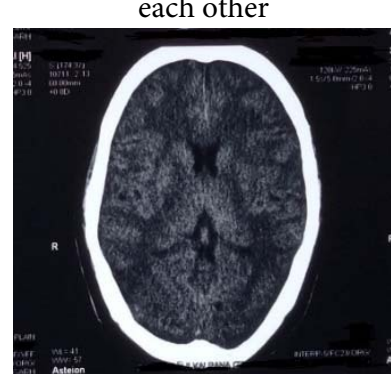

Figure 3B - complete resolution of bilateral basal ganglia Hemorrhage

\section{Case 4}

35 year old Female was admitted in neurosurgery ward with head injury in unconscious state. There was no history of ear bleed, nose bleed, convulsion, CSF leak. There was no any history suggestive of bleeding disorder. Patient was a non-diabetic nonhypertensive. Prior to the accident, he was not on any medication. His GCS was E2V3M5. Pupils were $2 \mathrm{~mm}$ bilaterally, reacting to light. Bilateral limb movement was equal. A plain Computerized Tomogram showed Deep Intracerebral bleed [Figure 4A] in the bilateral basal ganglia which was mirror image to each other. Basal cisterns were normal and no midline shift. All blood parameters and clotting profile were within normal limits. Phenytoin sodium was given. 2nd of admission patient became conscious, oriented \& GCS was 15/15 and no focal neurological deficit, then Patient was discharge 5th of admission. 3 month of follow up of patient was alright without any neurological deficit and advised repeat NCCT head which revealed complete resolution of Hemorrhage [Figure 4B].

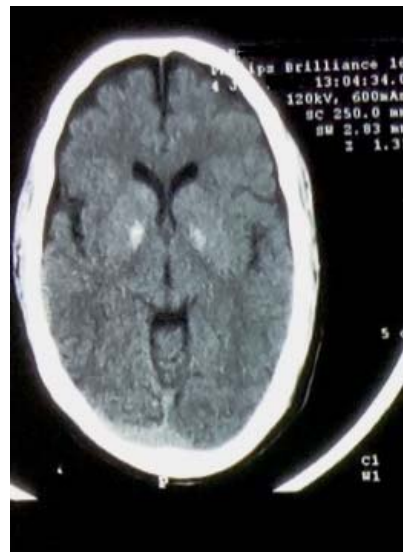

Figure 4A - Showed Deep Intracerebral bleed in the bilateral basal ganglia which was mirror image to each other

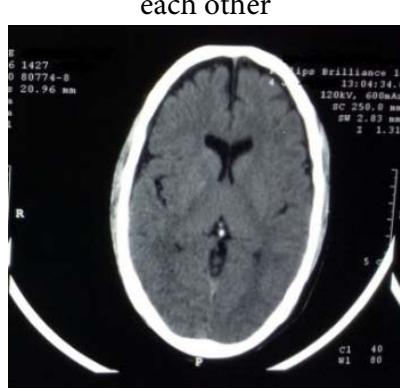

Figure 4B - Complete resolution of bilateral basal ganglia Hemorrhage

\section{Case 5}

30 year old Male, came with a road traffic accident. He was admitted in neurosurgery ward in unconscious state. His GCS was E3V3M6. Pupils were $2 \mathrm{~mm}$ bilaterally, reacting to light. Bilateral limb movement was 
equal. A plain Computerized Tomogram showed small Deep Intracerebral bleed [Figure 5A] in the bilateral basal ganglia basal cisterns were normal and no midline shift. Phenytoin sodium was given. 2nd of admission patient became conscious, oriented \& GCS was 15/15 and no focal neurological deficit, then Patient was discharge 5th of admission. 3 month of follow up of patient was alright without any neurological deficit, and advised repeat NCCT head which revealed complete resolution of Hemorrhage [Figure 5B]. Patient still in follow up, he has not any deficit.

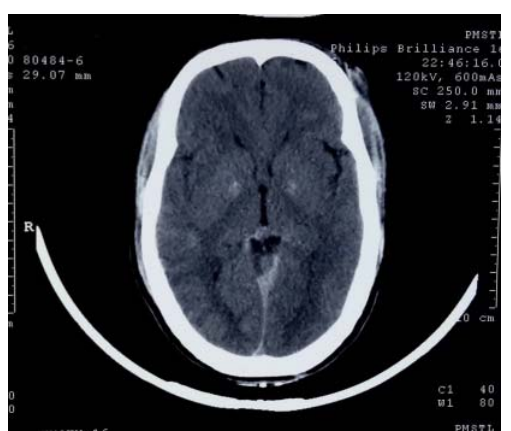

Figure 5A - Small Deep Intracerebral bleed in the bilateral basal ganglia

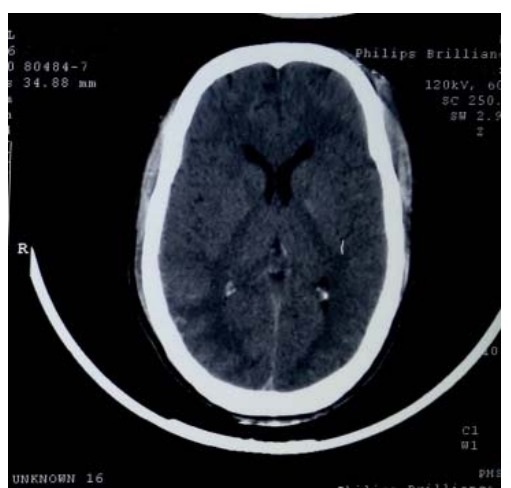

Figure 5B - Complete resolution of bilateral basal ganglia Hemorrhage

\section{Discussion}

The general incidence of TBGH is reported between 2.4-3\% [1,3, and 7] of closed head injury. However, the incidence is higher in post mortem studies $(9.8 \%)$. [1,3] Bilateral traumatic basal ganglia hematoma is extremely rare. Descriptions are limited to case reports [1,2,4, and 5], However, Kumar et al. found one patient with bilateral basal ganglia bleed amongst 10 cases of TBGH (10\%) [8].

It was previously believed that $\mathrm{TBGH}$ were small, multiple, sometimes bilateral and located in the zone of lentiform nucleus and external capsule, whereas spontaneous hemorrhages were large solitary, large causing mass effect and in the region of thalamus and internal capsule. A patient suffering from a head injury and having a lesion of the latter type was considered to be due to a spontaneous bleed causing the event [9].

Later on, in a patient of fatal severe head injury, Mosberg et al. [10] at autopsy confirmed a massive hematoma in the palladium and a ruptured twig of the anterior choroidal artery. After histopathology, the arterial tear was confirmed to be traumatic. Maki et al. [11] (1980), reported TBGH, where the mechanism was supposed to be anterior stretch of the lateral branch of the perforator of the middle cerebral artery. Kinoshita et al. [12] (2008) have also postulated anterior choroidal artery causing basal ganglia bleed. Fujioka et al. [13] have demonstrated that the traumatic dissection of the middle cerebral artery causing 
hemorrhage and infraction in the basal ganglia and thalamus.

In both our patients, there was a clear cut history of trauma, and no evidence, historically, clinically, and radiologically to suggest any other cause of this lesion, thereby confirming it to be TBGH. However, in the second case, the age may favor hypertensive bleed, but his blood pressure had been normal during his inpatient stay.

It has been postulated that if trauma occurs while the head is in motion, and the impact sufficient to deform the skull is applied to the vertex, forehead or occipital area and directed to the tentorium, it shifts the brain through the tentorial notch, producing shearing forces leading to the damage to the vessels described above. Both coup and countercoup injuries can cause this and this may cause bilateral lesions [13]

TBGH may be classified as large if more than $2 \mathrm{~cm}$ in diameter or small if less than 2 $\mathrm{cm}$ in diameter [1,3]. Small lesions in the basal ganglia have also been described as a part of diffuse axonal injury. However, the mechanism is shearing strain on the axons and it also involves the cerebral white mater, corpus callosum, and upper brainstem [14, 15].

Treatment is based on protocol as for intracranial hematoma taking into account the neurological status, presence of mass effect and response to other means of controlling ICP. Treatment options for TBGH include conservative, open surgery, CT guided stereotactic or ultrasound guided aspiration [6]. Boto et al. [6] recommend surgical evacuation for all lesions having a volume greater than $25 \mathrm{ml}$. In the series by Kumar et al. [8] all the patients were managed conservatively (average volume $13.2 \mathrm{ml}$ ). However, all patients had a volume less than $25 \mathrm{ml}$ (maximum 23ml). In the case of bilateral TBGH by Jang et al. [4] the patient had a GCS of 15 and hence was conservatively managed.

Outcome of TBGH has been found to be variable. Amongst 37 patients studied by Boto et al. [6] 59\% died, $5 \%$ were vegetative, 19\% experienced severe disabilities, and $16 \%$ made a favorable recovery. In contrast, in a study of 10 patients by Kumar et al. [8] all patients had a favorable outcome (Glasgow Outcome Score of 4 or 5) and mortality was nil. Katz et al. [16] Kimura et al, [17] Lee et al. [18] Jang et al. [4] have also reported good prognosis for TBGH, we mentioned all previous reported case in (Table-3). Large size, associated coagulation disorders, DAI, presence of other bleeds like intraventricular of brain stem hemorrhage, age greater than 60 , abnormal pupillary response, abnormal motor response to pain, and severe head injury are reported to be indicators for poor prognosis[3,7,8,18]. Kankane et al reported bilateral traumatic basal ganglia bleed and both the patient managed conservatively and outcome was good and no focal neurological deficit[19] Zhang YX, et al reported single case of 45 year female of traumatic bilateral traumatic basal ganglia bleed and patient managed conservatively and outcome was good and mild unilateral Hemiparesis [20]

Willem Guillermo et al reported a 28-year old man, a victim of car- accident have hyperdense lesion in the basal ganglia 
bilaterally, with the presence of right parietal epidural hematoma. Craniotomy and epidural hematoma drainage were considered, associated to conservative management of gangliobasal traumatic contusions. On day 7 the patient had sudden neurologic deterioration, cardiac arrest unresponsive to resuscitation. [21] Recently Jain and colleagues [22] reported a 38-year old fully conscious male, who presented with bilateral basal ganglia haematoma and extradural hematoma. The patient was also undergone craniotomy and hematoma evacuation

Pandey et al reported a 37-year-old man with traumatic left frontotemporal acute subdural hematoma, left side traumatic subarachnoid hemorrhage (TSAH) and bilateral BGH with punctuate hemorrhages in the corpus callosum. Left frontotemporoparietal Decompressive craniectomy was done in the emergency. The patient was on ventilatory support postoperatively and remained comatose. $\mathrm{He}$ was in the Neuro Intensive Care Unit for 2 weeks and also required tracheostomy. At discharge, 4 weeks after injury his GCS was E4VtrM2.outcome was poor. [23]

Moriya $\mathrm{T}$ reported [24] a case of traumatic hematoma in the basal ganglia multiple gliding contusions in the left frontal and parietal lobe in 65 year old male that showed deterioration after arrival at the hospital The patient died on the 13th day of trauma .

In our study all five patients had Isolated bilateral TBGH without secondary brain injury. All patients managed conservatively and had good outcome.

Table 3 - Description of previous reported cases

\begin{tabular}{|c|c|c|c|c|c|c|c|c|}
\hline $\begin{array}{c}\text { Serial } \\
\text { no. }\end{array}$ & Author & year & $\begin{array}{c}\text { No. of } \\
\text { case }\end{array}$ & $\begin{array}{l}\text { Age of } \\
\text { patient }\end{array}$ & $\begin{array}{l}\text { Sex of } \\
\text { patient }\end{array}$ & Description of patient & management & outcome \\
\hline \multirow{2}{*}{1} & \multirow{2}{*}{ Yanaka k et al } & \multirow{2}{*}{1991} & \multirow{2}{*}{2} & 17 year & Male & TBBGH & Surgical & Good \\
\hline & & & & 75 year & Male & TBBGH & Conservative & Good \\
\hline \multirow{2}{*}{2} & \multirow{2}{*}{ Kimura $\mathrm{M}$ et al } & \multirow{2}{*}{1994} & \multirow{2}{*}{2} & Adult & Male & TBBGH & Conservative & Good \\
\hline & & & & Adult & Male & TBBGH & Conservative & Good \\
\hline 3 & Kumar et al & 2009 & 1 & 35 & Female & TBBGH & Conservative & Fair \\
\hline \multirow{2}{*}{4} & \multirow{2}{*}{ Bhargava et al } & \multirow{2}{*}{2012} & \multirow{2}{*}{2} & & Male & TBBGH & Conservative & Good \\
\hline & & & & & Male & TBBGH & Conservative & Good \\
\hline \multirow[t]{2}{*}{5} & \multirow[t]{2}{*}{$\begin{array}{c}\text { Kankane vk et } \\
\text { al }\end{array}$} & \multirow[t]{2}{*}{2016} & \multirow[t]{2}{*}{0} & $20 \mathrm{yr}$ & Male & $\begin{array}{c}\text { Traumatic bilateral } \\
\text { basal ganglia bleed } \\
\text { (TBBGH), Right side } \\
\text { hemiparesis, GCS 9/10 }\end{array}$ & Conservative & Good \\
\hline & & & & $40 \mathrm{yr}$ & Male & $\begin{array}{c}\text { TBBGH ,Lt side } \\
\text { hemiparesis, GCS 9/10 }\end{array}$ & Conservative & Good \\
\hline 6 & Zhang YX & 2016 & 1 & $45 \mathrm{yr}$ & Female & TBBGH & Conservative & Good \\
\hline 7 & Willem & 2014 & 1 & $28 \mathrm{yr}$ & male & TBBGH with epidural & Craniotomy & Death \\
\hline
\end{tabular}


330 | Gupta et al - Traumatic bilateral basal ganglia Hemorrhage

\begin{tabular}{|c|c|c|c|c|c|c|c|c|}
\hline & Guillermo et & & & & & Haematoma & & Good \\
\hline 8 & Jain SK et al & 2013 & 1 & 38 year & male & $\begin{array}{c}\text { TBBGH with epidural } \\
\text { Haematoma }\end{array}$ & Craniotomy & Poor \\
\hline 10 & Pandey et al & 2014 & 1 & 37 year & male & $\begin{array}{c}\text { TBBGH with acute } \\
\text { subdural hematoma }\end{array}$ & Craniotomy & Death \\
\hline 11 & Present study & 2017 & 5 & $\begin{array}{c}20 \mathrm{yr}, 40 \mathrm{yr}, \\
35 \mathrm{yr}, 25 \mathrm{yr}, \\
30 \mathrm{yr}\end{array}$ & $\begin{array}{c}3 \text { Male } \\
\text { and } 2 \\
\text { Female }\end{array}$ & $\begin{array}{c}\text { TBBGH with multipal } \\
\text { contusion }\end{array}$ & Conservative & TBBGH \\
\hline
\end{tabular}

\section{Conclusions}

Traumatic BGH is rarely reported, and bilateral $\mathrm{BGH}$ is very rare entity only few cases reported in world's literature. We reported consecutive 5 cases in a single institute in first time in world literature. BGHs are Compatible with a favorable recovery if not associated with damage to other cortical and sub cortical structures and present in isolation. The BGHs seem to be hemorrhagic contusions as a result of a shearing injury due to high velocity impact. It can be managed conservatively. Prognosis is variable and dependant on many factors.

\section{Correspondence}

nehagupta8484@gmail.com (Neha Gupta)

vivekkankane9@gmail.com (Vivek Kumar

Kankane)

tkgupta59@hotmail.com (Tarun kumargupta)

\section{References}

1. Bhargava P, Grewal SS, Gupta B, Jain V, Sobti H. Traumatic bilateral basal Ganglia hematoma: A report of two cases. Asian J Neurosurg. 2012 Jul; 7(3):147-50

2. Jain SK, Sundar IV, Sharma V, Prasanna KL, Kulwal G, Tiwari R Bilateral large traumatic basal ganglia haemorrhage in a conscious adult: a rare case report. Brain Inj. 2013; 27(4
3. Adams G, Doyle D, Graham DI. Deep intracerebral (basal ganglion) hematomas in fatal non-missile injury in man. J Neurol Neurosurg Psychiatry. 1986; 49:103943.

4. Jang KJ, Jwa CS, Kim KH, Kang JK. Bilateral Traumatic Hemorrhage of the Basal Ganglia. J Korean outcomeNeurosurg Soc. 2007; 41:272-4

5. Yanaka K, Egashira T, Maki Y, Takano S, Okazaki M, Matsumaru Y, et al. Bilateral traumatic hemorrhage in the basal ganglia: report of two cases. No Shinkei Geka. 1991;19:369-737.

6. Boto GR, Lobeto $\mathrm{RD}$, Rivas J. Basal ganglion hematoma in severely head injured patients: Clinicoradiological analysis of 37 cases. J Neurosurgery. 2001;94:224-25.

7. Katz DI, Alexander MP, Seliger GM, Bellas DN. Traumatic basal ganglia hemorrhage: clinicopathologic features and outcome. Neurology. 1989; 39:897-04.

8. Kumar S, Jha D, Abbey P, Mishra V, Handa A. Outcome of Traumatic Basal Ganglia Hemorrhage. Internet J Neurosurg. 2009:61.

9. Courville CB, Blomquist OA. Traumatic intracerebral hemorrhage: with particular reference to its pathogenesis and its relation to "Delayed traumatic apoplexy” Arch Surg. 1940;41:1-28.

10. Mosberg WH, Lindenberg R. Traumatic hemorrhage from the anterior choroidal artery. J Neurosurg. 1959; 16:209-21.

11. Maki Y, Akimoto H, Enomoto T. Injuries of Basal Ganglia following Head Trauma in Children. Childs Brain. 1980; 7:113-23.

12. Kinoshita Y, Yasukouchi H, Harada A, Tsuru E, Okudera T. Case report of traumatic hemorrhage from the anterior choroidal artery, No Shinkei Geka. 2008;36:891-4 
13. Fujioka M, Maeda Y, Okuchi K, Kagoshima T, Taoka T. Secondary Change in the Substantia Niagra Induced by Incomplete Infarct and Minor Hemorrhage in the Basal Ganglia Due toTraumatic Middle Cerebral Arterial Dissection. Stroke. 1999;30:1975-7

14. Lindenberg R. Trauma of meninges and brain. In: Minckler J, editor. Pathology of the Nervous System. Vol. 2. New York: McGraw-Hill; 1971. pp. 1705-65.

15. Shimura T, Nakazawa S, Kobayashi S, Yokota H, Otsuka T, Nakamura T. Clinicopathological studies of diffuse axonal injury-five autopsy cases. No Shinkei Geka. 1988;16(5 Suppl):647-53

16. Katz DI, Alexander MP, Selinger GM. Traumatic basal ganglion hemorrhage: clinicopathologic features and outcome. Neurology. 1989;39:897-904

17. Kimura M, Sobata E, Suzuki S. Traumatic basal ganglion (caudate) with favorable prognosis: Report of two cases. No Shinkei Geka. 1994;22:155-8.

18. Lee JP, Wang ADJ. Post-traumatic basal ganglia hemorrhage: Analysis of 52 patients with emphasis on the final outcome. J Trauma. 1991;31:376-80.

19. Kankane VK, Gupta TK, Jaiswal G. Traumatic bilateral basal ganglia bleed: A report of rare two cases and review of the literature. Asian J Neurosurg 2016;11:457.
20. Zhang YX, Wei SQ, Xing YY, Liu Q, He WJ Bilateral traumatic hemorrhage of the basal ganglia.Chin J Traumatol. 2016 Aug 1;19(4):247-8

21. Willem Guillermo Calderon-Miranda, Hernando Raphael Alvis-Miranda, Gabriel Alcala-Cerra, Andres M. Rubiano, Luis Rafael Moscote-Salazar: Bilateral Traumatic Basal Ganglia Hemorrhage Associated With Epidural Hematoma: Case Report and Literature Review. Bull Emerg Trauma. 2014 Jul; 2(3): 130-132.

22. Jain SK, Sundar IV, Sharma V, Prasanna KL, Kulwal G, Tiwari RN. Bilateral large traumatic basal ganglia haemorrhage in a conscious adult: a rare case report. Brain Inj. 2013;27(4):500-3

23. Nityanand Pandey, Ashok Mahapatra, and Pankaj Kumar Singh: Bilateral large traumatic hemorrhage of the basal ganglion. Asian J Neurosurg. 2014 Oct-Dec; 9(4): 240.

24. Moriya T, Tagami R, Furukawa M, Sakurai A, Kinoshita K, Tanjoh K. A case of traumatic hematoma in the basal ganglia that showed deterioration after arrivalat the hospital. Acta Neurochir Suppl. 2013;118:147-9. 